\title{
O CUIDADO DE SI EM ALCEBÍADES E LINHAS PARALELAS TRAÇADAS NAS PRÁTICAS EDUCATIVAS DA EDUCAÇÃO INFANTIL: A EXPERIÊNCIA DE SER UM BEBÊ E UMA CRIANÇA NEGRA NA CRECHE
}

\author{
Natália Lopes dos Santos ${ }^{1}$
}

\section{Apresentação}

\begin{abstract}
A experiência, e não a verdade, é o que dá sentido à escritura. Digamos, com Foucault, que escrevemos para transformar o que sabemos e não para transmitir o já sabido. Se alguma coisa nos anima escrever é a possibilidade de que esse ato de escritura, essa experiência em palavras, nos permita liberar-nos de certas verdades, de modo a deixarmos de ser o que somos para ser outra coisa, diferentes do que vimos sendo. Jorge Larrossa e Walter Kohan, 2015
\end{abstract}

O excerto, escrito por Jorge Larrosa e Walter Kohan, retirado do livro "O Mestre Ignorante: cinco lições sobre a emancipação intelectual”, de Jacques Rancière (2015), descreve com muita fidelidade, o sentido que orienta a escrita deste texto. Pode-se, de antemão afirmar, que a escrita não fora planejada como meio de fixar verdades permanentes, interessa mais, através da reflexão proposta por Foucault (1982), expor outras perspectivas e outros caminhos possíveis de observar fenômenos que ocorrem nos contextos da educação infantil e a partir de então, repensarmos concepções, práticas e ações pedagógicas que são desenvolvidas nas instituições educacionais que se ocupam com o educar e cuidar de bebês e crianças pequenas.

Pensando na experiência de ser uma criança negra, na institucionalização do racismo que entrelaça as relações sociais, imprime moldes de estruturas sociais e dissemina os perigos de uma história única em espaços coletivos, como centros municipais de educação infantil, escolas, comunidades etc., e que colaboram e integram o processo de formação do indivíduo, cogitou-se a possibilidade de, à partir do texto de Alcibíades em sua última parte mencionado por Foucault nas primeiras aulas do curso A hermenêutica do sujeito, no Collège de France, 1982, estabelecer o diálogo entre a noção do cuidado de si, como forma de reflexão sobre práticas e fenômenos que configuram as práticas de subjetividade que atuam com a lógica de produzir o indivíduo nos espaços educacionais, e questões que envolvem o fazer pedagógico na educação infantil. Para isso, pretende-se iniciar a conversa apresentando primeiramente breves considerações relativas à teoria do cuidado de si. Posteriormente, será traçado um linear dos acontecimentos que configuraram a trajetória social e acadêmica de Alcibíades e que o levaram ao despertar da ação do cuidado de si, e a partir de então, será proposto ao leitor um diálogo para refletirmos sobre a teoria do cuidado de si e questões raciais no ambiente da creche.

\footnotetext{
${ }^{1}$ Mestranda em Educação (FE-Unicamp). Especialista em Docência em Educação Infantil (UFSCar, 2016). Professora da CEMEI Anna Kerulis da Silveira - Catanduva-SP. E-mail: n211859@ dac.unicamp.br.
} 


\section{Impressões primárias sobre o cuidado de si}

A partir da leitura das aulas, tornadas em livro, do curso A hermenêutica do sujeito ministrado por Michel Foucault, no ano de 1982, no Collège de France, numa primeira aproximação do pensamento do autor, entende-se que a noção do cuidado de si desenvolvida na percepção de Platão, emerge como um fenômeno cultural de conjunto (incitação e aceitação geral do princípio de que é preciso ocupar-se consigo mesmo), característico da sociedade helenística e romana, ou pelo menos parte dela, e também como um princípio grego bastante complexo e rico, muito frequente, e que permaneceu durante toda a cultura grega, helenística e romana como fórmula fundadora de intermediar a relação entre sujeito e verdade. De um modo geral, a noção de epiméleia heautoû (cuidado de si) é tratada entre os filósofos da Antiguidade como princípio de conduta racional estabelecida a toda forma de vida ativa. Além de Platão, veremos a expressão sendo abordada nos textos estoicos, nos cínicos, nos epicuristas, nos pitagóricos, em Sêneca, Epicteto e no Cristianismo, todavia a discussão proposta neste trabalho remeter-se-á apenas ao seu momento de surgimento na visão socrática-platônica, terminologia assim adotada por Foucault (2006, p. 49).

Observa-se que no decorrer das aulas, o princípio do cuidado de si aparece reaclimatado por expressões como: ocupar-se consigo mesmo, ter cuidados consigo, retirar-se em si mesmo, recolher-se em si, sentir prazer em si mesmo, buscar deleite somente em si, estar em si como numa fortaleza, cuidar-se, prestar culto a si mesmo, respeita-se etc. De todo modo, em todo o pensamento antigo, tais vocábulos receberam sempre conotações com valores positivos, estabelecendo-se como requisito fundamental para alcance do acesso a verdade. Verifica-se também que, desde a apresentação de Sócrates como promotor pioneiro até limiar do ascetismo cristão, variadas formas de interpretar e empregar foram atribuídas a noção do cuidado de si. No entanto, quatro pontos importantes perduram-se durante a trajetória milenar evolutiva.

O primeiro ponto seria o de compreender o cuidado de si como uma atitude geral, como uma forma de olhar e perceber as coisas do mundo e praticar ações que envolva o cuidado de si nas relações com o outro, consigo mesmo e com o mundo. Segundo ponto, receber o cuidado de si como uma possibilidade de estar atento ao que se passa no pensamento e converter o olhar para si mesmo. Terceiro ponto, assumir ações pelas quais podemos nos modificar, nos purificar, nos transformar e nos transfigurar à medida que sejamos capazes de tomar consciência do que fazemos ou deixamos de fazer nas ações desenvolvidas. Quarto e último ponto é, para que haja efeitos, a prática do cuidado de si tem a necessidade da presença de um mestre, alguém que, mantido pelos laços da amizade, cuida do cuidado que o sujeito precisa ter para consigo. É a pessoa incumbida de propiciar ao indivíduo o diálogo necessário para viabilizar o acesso ao saber essencial para um bom governo de si.

Averígua-se a partir de então, que o princípio do cuidado de si configura-se como um conjunto de práticas, formas de reflexão que na maioria das vezes, por intermédio da ajuda do outro, se efetivam com exercícios espirituais que envolvem meditação, técnicas de memorização e exame de consciência. Nas palavras de Foucault, o tema do cuidado de si apresenta uma formulação filosófica precoce e por assim dizer:

[...] com a noção de epiméleia heautoû, temos todo um corpus definindo uma maneira de ser, uma atitude, formas de reflexão, práticas que constituem uma espécie de fenômeno extremamente importante, não somente na história das representações, nem somente na história das noções ou das teorias, mas na própria história da subjetividade ou, se quisermos, na história das práticas da subjetividade (FOUCAULT, 2006, p. 15). 
Como já mencionado anteriormente, na sua origem primária o imperativo "cuida de ti" entreteceu-se como uma sentença antiga dada na cultura grega, sendo manifestada a priori, por pessoas com prestígio social, político e econômico, os então chamados lacedemônios, que se portando de escravos (hilotas, na cultura grega), para confiarem o trabalho de cultivo às suas terras, investiam tempo ocupando-se consigo mesmos, nutrindo assim, a expectativa de cuidar de si para poder ser capaz de governar os outros. Nesse sentido, a educação espartana pautouse em referenciais que assegurariam a formação do sujeito em boas maneiras, grandeza de alma, coragem, resistência, apreço pelo exercício e fascínio por vitórias e honras.

Considerado como momento de o primeiro despertar, o cuidado de si fora, a princípio, destinado a jovens em fase de transição, ou seja, quando se estaria saindo das mãos dos pedagogos e iniciando o período de atividade política. $\mathrm{Na}$ Antiguidade, essa fase corresponderia ao intervalo entre 20 a 30 anos, quando efetivamente, estaria sendo finalizado o transcorrer da infância. Entretanto, não sendo possível o incitar do cuidado de si na etapa de vida recomendada, Epicuro anunciara a boa notícia de que nunca seria tarde ou cedo demais para exercer o cuidado de si. Veremos longo mais adiante que Alcibíades fora iniciado ao cuidado de si estando ele na idade de cinquenta anos.

Em suma, compreende-se que o cuidado de si constitui não somente como um princípio, mas como um conjunto de práticas constantes que devemos perseguir ao longo de toda a vida, ocuparmos com o cuidado de nossas almas. Envolve em alguns momentos a ação de caminhar na direção oposta, retornar para si mesmo, converter-se para si em busca do sentido pleno da vida.

\section{O cuidado de si em Alcibíades e possíveis práticas educativas deformadoras adotadas na educação de bebês e crianças negras no ambiente da creche}

Notamos através do entendimento de Foucault (2006, p. 41), que na reflexão filosófica, a teoria do cuidado de si acolhe como nascedouro o desfecho do diálogo intitulado Alcibíades. Sócrates, obedecendo às instruções dos deuses e estando ele na posição de senhor do cuidado de si, se aproxima de Alcibíades carregando consigo a suposição de que, sendo Alcibíades colocado à prova diante da interpelação: morrer hoje ou continuar a levar uma vida sem brilho algum? Alcibíades responderia mediante a seguinte afirmação: prefiro morrer hoje a levar uma vida que não me trouxesse nada além do que já tenho. Para melhor compreendemos a decisão de Alcibíades, será descrito em seguida alguns pormenores sobre status e características de sua pessoa.

Conforme nos relata Foucault (2006, p. 43), a personalidade ateniense pertencia a uma das famílias mais empreendedoras da cidade. Desfrutou de relações entre amigos parentes ricos, poderosos e com boas influências no campo social. Sendo órfão, possuía uma fortuna considerável. Sua aparência física era julgada como bela, atraente, encantadora, acarretandolhe um exacerbado assédio por parte dos rapazes. Detentor de um temperamento arrogante, Alcibíades desprezou todos os seus admiradores, e estando em idade avançada, apaixonou por Sócrates, que tomado pelo seu ofício designado pelos deuses, manteve-se firme e não se permitiu ser seduzido pelo seu discípulo.

$\mathrm{Na}$ medida que Sócrates percebe o desejo voraz de Alcibíades em querer fazer valer seus privilégios de primazia estatutária para governar a cidade, o mestre sábio incita o jovem sôfrego a estudar um pouco mais de perto suas fragilidades e deficiências. A partir do diálogo, Alcibíades é provocado por Sócrates a perceber sua condição precária inicial para exercer a ação política. Embora rico, após a morte de seus pais, Alcibíades fora confiado a Péricles, personalidade política influente na Grécia antiga, mas, no entanto, pouco soube administrar a educação de seus dois filhos. Péricles elegeu um escravo que, ao o que tudo indica, deveria reter pouca formação acadêmica para ser tutor de Alcibíades. A partir dessa referência, Sócrates 
realiza o exercício de tentar mostra a Alcibíades, comparando-o aos espartanos que recebiam uma educação de excelência, a ausência de habilidades específicas na sua formação humana que o ajudariam bem governar um povo. Inevitavelmente, seria necessário tentar remediar tais inferioridades iniciais. Alcibíades então, sendo convencido pelo discurso de Sócrates, se submete as instruções do mestre que, ocupando-se com as ignorâncias de seu discípulo, formula estratégias instalar as técnicas do cuidado de si. Este, portanto, seria o ponto inicial da teoria do cuidado de si. Aprende-se no texto de Sócrates e Alcibíades que, para exercer a ação de governar o outro, primeiro é essencialmente preciso que se ocupe consigo mesmo, conheça quem realmente você é, e desenvolva a prática de governo de si mesmo.

Feito esta breve apresentação do diálogo intitulado Alcibíades, buscar-se-á apontar alguns pontos críticos da formação de Alcibíades e mediante eles, traçar paralelos com algumas práticas educativas que vem sendo adotadas nos espaços destinados ao desenvolvimento da educação infantil. Não faz parte das intenções deste trabalho levantar juízo de valor entre um ou outro ponto abordado. Pretende-se através do exercício da escrita, instigar o leitor e todos/todas aquelas/aqueles que militam em favor de uma educação básica de qualidade, perceber por outros ângulos, formas de discutir e debater questões problemáticas que dificultam a ação de bem governar e administrar o cuidar e educar de bebês e crianças pequenas que frequentam o ambiente da creche, sobretudo, o cuidar e educar de bebês e crianças negras.

O primeiro elemento percebido e recrutado para estabelecer o diálogo entre cuidado de si e fenômenos ocorridos na educação infantil, será a crítica conferida à pedagogia e a prática educativa ateniense. Conforme elucida Marques (2012, p. 12), Esparta e Atenas, elegendo modelos políticos, sociais e culturais distintos, ocuparam o lugar de referência original no desenvolvimento da história da educação e da Pedagogia. De acordo com a autora, dois ideais de educação vieram à luz: um com viés militarista que preparava de modo homogêneo crianças e jovens para a arte da guerra (Esparta), e o outro com uma concepção de Paideia, objetivando uma formação humana livre e repleta de experiências diversas, respeitando a capacidade de construção do indivíduo acerca do mundo interior e social (Atenas). Todavia, a pedagogia e prática educativa ateniense comparada à educação espartana é criticada nos diálogos socráticos porque, conforme relata Foucault (2006, p. 56), os processos formativos em Atenas não conseguem estimular o amor pelos rapazes de forma a honrar a tarefa formadora. Ou seja, os jovens atenienses não são instruídos a permitir serem seduzidos por homens adultos que além de outras coisas, exerceram a função de mestre, espécie de guia para desenvolver a ação política. Devido a isto, a pedagógica ateniense será percebida na era helenística e romana como deficitária, deformadora, ineficiente.

Embora exposta de maneira superficial, a concepção adotada na educação ateniense aparenta transportar valores que, na visão atual dos ditos educadores progressistas, seria recebido como pontos positivos. No entanto, observa-se que na cultura grega antiga, tais valores são desqualificados. Reportando-se às pesquisas que reúnem questões raciais e práticas educativas hegemônicas no contexto da creche, simultaneamente a memória é conduzida a cenas corriqueiras que, na visão desta que lhes escreve, poderiam estar sendo enquadradas como deficitária, deformadora e ineficiente.

No sentido de convidar o(a) leitor(a) para refletir o que poderia estar sendo ou não uma prática deficitária, deformadora e ineficiente nos processos formativos dos dias atuais, e em específico, nas práticas educativas que se desenvolvem na educação infantil, apresento pesquisa que realizei no ano de 2016. Pensando na imagem do negro nos livros de literatura infantil destinados às crianças de 0 a 3 anos de idade e nas possíveis contribuições que estes estariam exercendo no processo de construção de identidade étnica do bebê negro/negra no contexto da creche, busquei fazer um levantamento bibliográfico (SANTOS, 2016) onde tive a oportunidade de debruçar sobre dois acervos de livros de literatura infantil selecionados pelo Programa 
Nacional Biblioteca na Escola (PNBE) 2014. Tais livros são distribuídos em rede nacional pelo Ministério da Educação e tem por objetivo inserir a criança pequena no mundo da escrita, promovendo a construção de conceitos éticos, estéticos, literários, imagéticos, sociais e culturais (BRASIL, 2014). Do total de 50 livros investigados, 29 apresentam personagens ilustrados como humanos no enredo de suas histórias, 19 histórias são confeccionadas acolhendo animais como personagens ilustrativos e 02 obras são imagens ilustrativas de objetos.

Dentre as 29 obras com personagens ilustrados como humanos, apenas 06 produções literárias apresentam personagens negros ilustrados em suas histórias, em apenas dois livros, o personagem ilustrado do homem negro estaria inserido no enredo da história, nas outras 04 obras as imagens são meramente ilustrativas. Foi possível identificar com essa pesquisa, a baixa representatividade da criança negra, do homem negro nos livros de literatura infantil recomendados pelo PNBE às crianças de 0 a 3 anos de idade. Tal resultado, nos traz a informação de que durante sua permanência no ambiente da creche, o bebê e a criança pequena negra poderiam estar sujeitos a um regime de exclusão dos processos históricos que ilustram a histórica, a cultural, a riqueza e a estética provinda dos países de origem da população africana e/ou afro-brasileira. A falta de referências durante o processo formativo faz com que o bebê negro e a criança negra avolumem para si, um conjunto de dificuldades que interferiram de modo negativo no processo de construção étnica, favorecendo a perpetuação de estereótipos.

A formação de Alcibíades foi considerada por Sócrates como deficitária porque não viabilizou durante sua trajetória de formação escolar a desenvoltura de habilidades e técnicas que seriam relevantes para aqueles que teriam a pretensão de governar. Alcibíades sendo interpelado por Sócrates teve a oportunidade de equiponderar as faltas e ausências incorporadas durante o processo de formação humana. Estando ele com cinquenta anos, recebeu a possibilidade de reparar os males da escassez de seus processos formativos. Retomando ao resultado da pesquisa aqui apresentada, tenho a impressão de que as carências arroladas no processo formativo levam o bebê e a criança pequena negra a ocupar a mesma posição de Alcibíades quando este percebe que o cuidado de si lhe é necessário porque existe um déficit pedagógico.

A diferença é que Alcibíades sendo adulto usufruir de um repertório amplo que tornar viável a percepção de que lhe necessário ocupar-se consigo mesmo no sentido pleno da expressão. Mas, e os bebês e as crianças pequenas negras que tal qual a Alcibíades estão sendo expostas a processo formativos que poderão lhe ser deficitários, deformadores e ineficientes? Haveriam possíveis formas de incitar o cuidado de si desde a tenra idade e evitar que possíveis deformações aconteçam em seus processos identitários? Estaríamos nós professores e professoras da educação infantil dispostos a ocupar-se e cuidar da fragilidade, da deficiência e escassez do outro? Essas são perguntas que deixo para reflexão do leitor.

\section{Referências}

BRASIL. PNBE na escola: literatura fora da caixa, guia 1 - educação infantil. Brasília: MEC/SEB, 2014.

FOUCAULT, M. A hermenêutica do sujeito. Tradução de M. A. Fonseca e S. T. Muchail. São Paulo: Martins Fontes, 2006.

MARQUES, V. R. B. História da educação. 1. ed., revisada. Curitiba: IESDE, 2012. 
SANTOS, N. L. A importância da literatura infantil no processo de construção de identidade da criança negra. Trabalho de conclusão de Curso de Especialização em Docência da Educação Infantil (orientação: Profa. Dra. Gabriela Tebet). São Carlos, UFSCar, 2016. 